\title{
Las regiones especiales de desarrollo: ¿Un modelo de gestión pública en Honduras?
}

René Humberto Aguilar*

\section{RESUMEN}

¿Por qué una propuesta como la ciudades modelo o RED, sin ningún fundamento científico en ninguna área del conocimiento,logra causar una reforma constitucional? Porque en la sociedad hondureña prevalece la demagogia política, el dogmatismo ideológico, el pensamiento mágico-religioso y la debilidad institucional, especialmente del Estado de derecho.

La finalidad del presente artículo es demostrar la importancia del conocimiento científicos en el campo del desarrollo regional, mediante teorías como: planificación por cuencas hidrográficas, nódulo/lugar central, polos de crecimiento, teoría de la localización, etc.; modelos de gestión pública, modelos de desarrollo económico, políticas públicas, etc. en el abordaje del desarrollo nacional, regional o local. Caso contrario ocurrirá lo que ha ocurrido: la ideologización y politización partidaria de desarrollo, ejemplo: ciudad modelo o regiones especiales de desarrollo (RED). Como profesional del área del desarrollo y mediante este artículo se intenta contribuir a enriquecer el abordaje de la problemática en cuestión.

Palabras clave: Modelo, modelo de gestión pública, Estado de derecho, gobernabilidad, transformación histórica del Estado, demagogia, ideologización, lógicas perversas, lógica "ciudad modelo".

\section{Abstract}

Why a proposal such as cities or RED model with no scientific basis in any area of knowledge, does cause a constitutional amendment? Because in Honduran society prevailing political demagoguery, ideological dogmatism, magical thinking, religious and institutional weaknesses, especially the rule of law.

The purpose of this paper is to demonstrate the importance of scientific knowledge in the field of regional development, through theories such as watershed planning, nodule / central, growth poles, location theory, etc.; Governance models, models of

\footnotetext{
* Universidad Nacional Autónoma de Honduras-Valle de Sula, UNAH-VS. Facultad de Ciencias Sociales creerhn@yahoo.com
} 
economic development, public policy, etc.; in addressing the national, regional or local. Otherwise happen what happened: the ideology of development, eg model city or special development regions (RED). As a professional in the area of development and through this article attempt help enrich the analysis of the problem in mention

Key words: Model, model of governance, rule of law, governance, state historic transformation, demagoguery, ideology, perverse logic, logic "model city." 


\section{INTRODUCCIÓN}

"¿Quieres decirme el camino que debo de tomar para salir de aquí? -Exclamo Alicia. Eso depende mucho del lugar al que quieres ir —dijo el gato.

Poco me preocupa a donde ir - dijo Alicia. Entonces poco importa el camino que tomes -replico el gato."

Lewis Carrol

La UNAH, en su política de investigación del año 2012-2016 ha definido como uno de los ejes prioritarios de investigación: Democracia y Gobernabilidad, conceptualizado como "las transformaciones históricas que ha experimentado el Estado hondureño, los avances, retrocesos y tareas pendientes, el contexto internacional, nacional y local en que se producen, la dinámica política, social e institucional de estas transformaciones y su efecto sobre la sociedad, el proceso de descentralización y la reconfiguración de lo local'" .

Entre las prioridades de este eje y como temas prioritarios se plantean: 1. Reforma del Estado: tamaño, cobertura y vacíos; 2 . Descentralización y gobiernos locales; 3. Lo local y la redefinición de límites territoriales; 4 . La reconfiguración de lo local y 5. Reformas legislativa, judicial, de defensa y de seguridad, fiscal y otras. Teniendo en cuenta el referente programático y conceptual institucional anterior se abordan las Regiones Especiales de Desarrollo (RED), en tanto "modelo de gestión pública, que es necesario adoptar ${ }^{2 n}$.

¿Qué son la RED y cuál es su articulación con las transformaciones históricas que ha experimentado el Estado hondureño? ¿Qué dinámica política, social e institucional de las transformaciones del Estado Hondureño contribuye a la creación de la RED? ¿Cómo contribuirá a la reconfiguración de lo local la RED dada su naturaleza urbana? Etc.

Estas y otras preguntas orientan el proceso de abordaje de la RED en tanto su dinámica contribuye a la "Reforma del Estado: tamaño, cobertura y vacíos y a la reconfiguración de lo local ${ }^{3 n}$. Se parte de que el elemento dinámico lo constituye la RED y su dinamismo influye en la transformación del Estado hondureño; lo cual nos ubica en presencia de un Estado de derecho débil y bajo una administración pública carente de un enfoque de desarrollo en términos nacionales, regionales 0

\footnotetext{
${ }^{1}$ UNAH. Prioridades de Investigación UNAH, 2012-2016. Ejes y Temas prioritarios.

${ }^{2}$ El decreto de Ciudad Modelo (Regiones Especiales de Desarrollo). Dictamen.

${ }^{3}$ UNAH. Prioridades de Investigación UNAH, 2012-2016. Ejes y Temas prioritarios.
} 
locales. La finalidad del presente artículo es demostrar la carencia de elementos científicos, a nivel teórico y metodológico, en el campo del desarrollo regional, mediante teorías como: planificación por cuencas hidrográficas, nódulo/lugar central, polos de crecimiento, teoría de la localización, etc. en el abordaje de la RED y lo que ha dado como resultado la ideologización del tema.

\section{Definición de las RED a nivel del Decreto de Ciudad modelo.}

El Decreto de Ciudad modelo — La ley—usa dos denominaciones para referirse a la RED: 1. Regiones Especiales de Desarrollo y 2. Ciudades modelos; ambos términos denominan al mismo modelo de gestión pública y/o ente. ¿Qué es un modelo de gestión pública y que es un ente? Para la ley, la RED, en tanto "ente" es: 1. Adopción de tecnologías y 2 . Ambiente estable que capte inversión nacional y extranjera, crea empleos, dotar a la población de servicios de educación, salud, seguridad pública y la infraestructura necesaria que permita una mejora real en las condiciones de vida de la región ${ }^{4}$.

La definición legal de Red, en tanto, "ente" es sinónimo de condiciones sociales y materiales que contribuyen al funcionamiento del capital-trabajo, y como efecto derivado, el capital crea empleo, dota a la población de servicios básicos, adapta tecnología y contribuye a mejorar las condiciones de vida de una población (trabajo) a nivel regional. La ley de creación de las de Red no define qué es modelo de gestión pública. En los considerados segundo y tercero apunta:

CONSIDERANDO: Que en la historia reciente de la humanidad algunas sociedades tan pobres como la nuestra han creado las condiciones para crecer aceleradamente convirtiéndose en sociedades desarrolladas y más equitativas mediante la adopción de modelos de gestión pública que descansan en el otorgamiento de altos grados de autonomía a ciertas regiones del país.

CONSIDERANDO: Que es necesario adoptar esos modelos de gestión para permitir al país competir en mejores condiciones y acelerar el cumplimiento de las metas del Plan de Nación.

¿Qué es un modelo de gestión? Un "modelo de gestión” es un esquema o marco de referencia para la administración de una entidad. Los modelos de gestión pueden ser aplicados tanto en las empresas y negocios privados como en la administración pública. Lo anterior implica que tanto el Estado, como institución público, y la

${ }^{4}$ El Decreto de Ciudad Modelo (Regiones Especiales de Desarrollo). Dictamen. 
empresa privada poseen y/o hacen uso de modelos de gestión basados en políticas, programas y proyectos; mediante la implementación de los cuales pretende alcanzar sus objetivos.

El modelo de gestión que utiliza el sector público es diferente del modelo de gestión del sector privado. Mientras el segundo se basa en la obtención de ganancias económicas; el primero pone en juego otras cuestiones, como el bienestar social de la población. De ahí que los considerando de la ley de creación de las de Red tengan como referente último el bien común mediante: realización del hombre, como persona humana, justicia, libertad, seguridad, estabilidad, pluralismo, paz y democracia representativa. La Ley también le confiere al modelo de gestión una tarea concreta: competir, como país, en mejores condiciones y acelerar el cumplimiento de las metas del Plan de Nación. Lo anterior lleva a una pregunta más general: ¿Cuál es el modelo de gestión del Estado de Honduras, en general y de la administración pública presidida por el Presidente Señor Porfirio Lobo, en particular?

Una respuesta a esta pregunta desde un marco teórico-metodológico a nivel científico debe tener como referentes el paradigma burocrático de la racionalidad de Max Weber y/o el referente del modelo de gobernanza. El contenido de la Ley de creación de las RED, el proceso de socialización de la misma y la observación empírica de los treinta meses de gobierno de la administración pública presidida por el Señor Porfirio Lobo, no permite afirmar en forma tajante que se esté en presencia de uno u otro modelo de gestión pública. Es en estas condiciones de "... los avances, retrocesos y tareas pendientes del Estado hondureño en el contexto internacional, nacional y local..." que las palabras de David Wessel, redactor de la noticia "El sueño de una "ciudad modelo" como Hong Kong en Honduras" en el The Wall Street Journal Americas, adquieren pleno sentido: "Durante el último par de años Paul Romer ha recorrido el planeta en busca de un país lo suficientemente desesperado como para intentar poner en práctica su audaz idea: fundar una "ciudad modelo", un enclave libre de viejas leyes y prácticas".

El Estado de Honduras desde hace algunas administraciones, tiempo atrás, y la actual presidida por el Sr. Porfirio Lobo, carece de un modelo de gestión pública. El Estado de Honduras y con ello la sociedad hondureña "no vamos"; otras van y a nosotros nos llevan.

\footnotetext{
${ }^{5}$ UNAH. Prioridades de Investigación UNAH, 2012-2016. Ejes y Temas prioritarios.

${ }^{6}$ La Prensa. (3:02:10)
} 
En ese denominado proceso de "transformaciones históricas que ha experimentado el Estado hondureño", a criterio de las prioridades de investigación de la UNAH, consideramos que la fase más dinámica de los últimos treinta años la produjo la administración del Ex Presidente Licenciado Rafael Leonardo Callejas (1990-1994) y a partir de dos actores externos: Acuerdo de Esquipulas y Fondo Monetario internacional. No son los actores hondureños: gobierno, en tanto administrador público, y/o la sociedad, los que crean y/o adopta un modelo de gestión pública; son los actores externos los que nos indican que es lo más conveniente. De ahí que tengamos nuestras reservas con la afirmación institucional de la UNAH: "las transformaciones históricas que ha experimentado el Estado hondureño".

¿En qué tiempo histórico y en qué cuadro diacrónico-sincrónico se han dado esas transformaciones históricas que ha experimentado el Estado hondureño? Como parte de la mentalidad y lenguaje neoliberal el concepto modelo de gestión pública ha adquirido valides institucional y científico; se trata de un producto exportado por organismos económicos internacionales, principalmente el Banco Mundial y el Fondo Monetario Internacional, pero destacan especialmente las Organizaciones de Cooperación para el Desarrollo Económico (OCDE) cuyas administraciones en operación en el mercado deben calcular precios, hacer de sus oficinas centros productivos y estimular competitividad.

No se desconoce la importancia de los modelos de gestión pública y de hecho el modelo de la racionalidad burocrática de Max Weber — modelo clásico- y el modelo centrado en la gestión de riesgos ambientales, científicos y tecnológicos -modelo de gobernanza - constituyen importantes herramientas teóricas para abordar problemas de gobernabilidad, democracia, participación, etc. en nuestras sociedades.Consideramos que la propuesta de orden jurídico y la posterior aprobación de la Ley de las RED por parte de la administración del Presidente Sr. Porfirio Lobo; además de las críticas a esta iniciativa de gestión pública no han tenido como referente un conocimiento científico, sino una visión y un discurso ideológica. De ahí que no lo abordaremos desde los modelos de gestión pública.

\section{El origen de una "audaz" idea: fundar una "ciudad modelo"en Honduras.}

Se toma como punto de referencia dos noticias editadas por diario La Prensa: una, el día jueves 3 de febrero del 2011, tomada de The Wall Street Journal Americas y

\footnotetext{
${ }^{7}$ UNAH. Prioridades de Investigación UNAH, 2012-2016. Ejes y Temas prioritarios.

${ }^{8}$ IBIDEM

${ }^{9}$ La Prensa. (3:02:10)
} 
titulada: "El sueño de una "ciudad modelo" como Hong Kong en Honduras ${ }^{10, ;}$; la otra, editada el día viernes 4 de febrero del mismo año y bajo el siguiente titular: "Viaje. Corea del Sur y Singapur serán los países que visitará. Lobo viajará a Asia para conocer ciudades modelo ${ }^{11 "}$.

La propuesta y posterior aprobación en Ley de las denominadas ciudades modelo/regiones especiales de desarrollo en Honduras han causado mucho revuelo, por ende mucho discurrir ideológico. Las bondades y defectos al respecto han ido: desde constituirnos en el moderno Hong Kong de América Latina hasta la pérdida de nuestra soberanía a manos del capital internacional. Llama la atención la indefinición teórica y metodológica a lo largo de las discusiones ideológicas, de lado y lado: a favor o en contra; es decir la carencia de un debate científico al respecto. Xavier Arguello" "reconoce que a estas alturas hay muchas más preguntas que respuestas y que requerirían de un debate público ${ }^{13 \prime \prime}$.

Es interesante la diferencia entre ambas noticias. En la primera, la "ciudad modelo" es un sueño construido a partir de "algo parecido a lo que los británicos hicieron en Hong Kong". En la segunda noticias, la "ciudad modelo" es una realidad, así lo dijo el Presidente Porfirio Lobo: "Este 18 de febrero voy para Corea del Sur, pues ellos tienen experiencia con estas regiones de desarrollo, allá hay 150 ciudades especiales que, en el mundo han sido exitosas, entonces vamos a Corea del Sur y luego a Singapur" ${ }^{14 "}$.

David Wessel, redactor de la noticia "El sueño de una "ciudad modelo" como "Hong Kong en Honduras" en el The Wall Street Journal Americas, inicio su columna diciendo: "Durante el último par de años Paul Romer ha recorrido el planeta en busca de un país lo suficientemente desesperado como para intentar poner en práctica su audaz idea: fundar una "ciudad modelo", un enclave libre de viejas leyes y prácticas ${ }^{15}$. Es un hecho que el indicador planteado por David Wessel califica a la sociedad hondureña; una sociedad que vive una profunda crisis en todo sentido y que adquiere mayor expresión social a nivel económico y político; los hechos del 28

\footnotetext{
${ }^{10}$ La Prensa (3:02:10) "El sueño de una "ciudad modelo" como Hong Kong en Honduras". Pág. 70.

${ }^{11}$ La Prensa. (4:02:10) "Viaje. Corea del Sur y Singapur serán los países que visitará. Lobo viajará a Asia para conocer ciudades modelo". Pág. 20

${ }^{12}$ La Prensa. (3:02:10) "Arguello que fue asesor de un anterior presidente hondureño y ahora trabaja en una empresa inmobiliaria de Estados Unidos, llamo a Romer. Su grupo, en el que figuraba Juan Orlando Hernández, Presidente del Congreso hondureño, se reunió con Romer en Washington. Unas semanas después, Romer se encontró con Lobo y sus colaboradores en un hotel de Miami". La Prensa. (3:02:10)

${ }^{13}$ IBIDEM

${ }^{14}$ LaPrensa. (4:02:10)

${ }^{15}$ La Prensa. (3:02:10
} 
de junio del año 2009 no son la causa, sino un elemento más que profundizo la crisis de una nación, de un Estado, de un modelo económico, de una institucionalidad; al punto que hoy tenemos un nuevo calificativo internacional a nivel periodístico: "país lo suficientemente desesperado".

Wessel enumere algunos factores de esa "desesperación": 1. Creciente proceso migratorio hacia Estados Unidos; 2. Reputación internacional dañada; 3. Caótica expulsión de su Presidente (Sr. Manuel Zelaya Rosales) en el 2009; 4. Sube la tasa de homicidio y 5 . Estancia de la ruta del narcotráfico ${ }^{16}$. El debate, como bien se plantea en la noticia: "Viaje. Corea del Sur y Singapur serán los países que visitará. Lobo viajará a Asia para conocer ciudades modelo", hay que plantearlo en el terreno de las teorías del desarrollo regional y nacional.

La política de investigación del año 2012-2016 de la UNAH ha definido como un eje prioritario de investigación: Democracia y Gobernabilidad; dentro del eje y como temas prioritarios: 1. Reforma del Estado: tamaño, cobertura y vacíos; 2. Descentralización y gobiernos locales; 3. Lo local y la redefinición de límites territoriales; 4. La reconfiguración de lo local y 5 . Reformas legislativa, judicial, de defensa y de seguridad, fiscal y otras.

Teniendo en cuenta lo anterior es importante preguntarse: ¿El denominado modelos de gestión pública que descansa en el otorgamiento de altos grados de autonomía a ciertas regiones del país y denominado a nivel jurídico como RED incide en la democracia y gobernabilidad de la sociedad hondureña? ¿Constituye la RED una reforma del Estado? ¿Qué incidencia tendrán la RED en la redefinición de límites territoriales y la reconfiguración de lo local? ¿Cómo reformas legislativa que impacto tiene la Ley de las RED en el orden judicial nacional y/o en la descentralización y en la labor de los gobiernos locales? Etc. Estas y otra preguntas pretenden construir puentes entre la definición de una política de investigación institucional y una Ley que las actuales autoridades hondureñas esperan se transforme en un referente empírico concreto: ciudades modelos o RED; por los momentos se cuenta con la Ley, el referente empírico no existe en el territorio hondureño.

Señala Wessel que Romer "postula que las ideas o recetas, como prefiere llamarlas, son más importantes para el crecimiento de lo que se creía. (Parece simple pero es el tipo de hallazgo que lo podrían hacer acreedor de un Nobel $^{17}$ ).

\footnotetext{
${ }^{16}$ IBIDEM

${ }^{17}$ Op. Cit.
} 
Teniendo en cuenta este señalamiento de Romer, planteado por Wessel; el problema en debate con el modelo de gestión de una ciudad modelo o RED en Honduras no es el desarrollo, sino el crecimiento. La actual crisis que vivimos la sociedad hondureña pasa por esa diferencia básica entre desarrollo y crecimiento. En Honduras a partir de la década de los 90 y con la aplicación de los procesos de ajuste estructural en el país hubo crecimiento económico y modernización institucional; mas no hubo desarrollo socio-económico y democratización socioinstitucional. La crisis actual está ligada al agotamiento de ese modelo institucional.

Para algunos sectores que conciben el desarrollo como crecimiento económico lo que se necesita en Honduras es volver a tener crecimiento económico, he allí la importancia de las recetas. Ante situaciones desesperadas, acciones desesperadas. Wessel señala una vivencia de la desesperación de la administración del Presidente Porfirio Lobo. "Cuando las abstractas explicaciones de Romer no eran convincentes, alguien sugirió a Lobo que viera la conferencia. Lo hizo y se convenció". Xavier Arguello fundamenta aún más esta toma de decisiones a partir de ver un video. "Luego vieron un video en línea de una presentación de Romer. "En cuanto la vimos, supimos que era de lo que estábamos hablando". Cuenta XavierArguello ${ }^{18 n}$.

El Señor Porfirio Lobo merece todo el respeto en tanto ser humano, ciudadano y su investidura en función del cargo que ocupa; la descripción de la escena que hace Wessel es ofensiva para él y para el cargo que ocupa: 1. El Presidente de Honduras no fue convencido mediante el pensamiento abstracto de Romer, - "las abstractas explicaciones"- 2. Mediante una conferencia (video) -no se señala el tiempoquedo convencido de que esa es la receta para mejorara la perspectiva del país.

El convencimiento generado a partir de presenciar un video de una presentación de Romer es la causa de la reforma de los artículos 304 y 329 de la Constitución de la República. Para decirlo en términos de política de investigación de la UNAH: reformas legislativa. La reforma que el Congreso Nacional, presidido por el Abogado Juan Orlando Hernández, ha hecho de la Constitución de la República y planteada como un problema de democracia y gobernabilidad - eje prioritario de investigación de la UNAH_ n no forma parte de un modelo de gestión pública y/o de construcción de institucionalidad del Estado; sino de un problema de contención de la pobreza, la cual suele asociarse desde lecturas sociales con problemas de gobernabilidad y forma parte de las visiones estigmatizadoras de la pobreza difundidas en la UNAH, especialmente en el área de ciencia sociales de la UNAH-VS.

\footnotetext{
${ }^{18}$ Op. Cit.
} 
Dice el segundo y tercer considerando de la Ley de las RED:

CONSIDERANDO: Que la reducción de la pobreza y la marginalidad es posible lograrlo creando nuevas oportunidades de empleo, educación y salud al pueblo hondureño, en condiciones de sostenibilidad económica y ambiental.

CONSIDERANDO: Que en la historia reciente de la humanidad algunas sociedades tan pobres como la nuestra han creado las condiciones para crecer aceleradamente convirtiéndose en sociedades desarrolladas y más equitativas mediante la adopción de modelos de gestión pública que descansan en el otorgamiento de altos grados de autonomía a ciertas regiones del país.

Entre los conceptos planteados por la ley e importantes de abordar destacan los siguientes:

1) Los considerando tienen en cuenta la pobreza y marginalidad; no la democracia, no el Estado de derecho, no el desarrollo.

2) La Ley de las RED considera que el desarrollo y la equidad social no se construyen como proceso histórico, sino que se adoptan como modelos de gestión pública.

3) La Ley de las RED considera que la pobreza no es una construcción social y que se "desconstruye" a partir de la identificación y abordaje de las dinámicas sociales que la originan; sino que la respuesta a los problemas de pobreza es la creación de condiciones para crecer como el modelo de gestión pública que descansan en el otorgamiento de altos grados de autonomía a ciertas regiones del país.

4) El enfoque que subyace no es de construcción de Estado de derecho y/o de democracia, sino de gobernabilidad. Se identifica a la pobreza y marginalidad, no a los pobres, como factores que afectan la equidad social y con ello la estabilidad social, por ende la gobernabilidad.

He allí la razón porque no ha habido debate en torno al modelo de gestión pública de la ciudad modelo o RED. No existen argumentos del por qué, lo que existe es la necesidad de tener una receta para prometer y/o soñar con un crecimiento económico que posibilite, a largo plazo, un empleo a un pueblo desesperado "...en el que la mayoría de la gente quiere ir detrás del Sueño Americano ${ }^{19 n}$,(Migrar).

\footnotetext{
${ }^{19}$ Op. Cit.
} 
La ciudad modelo no ha sido un debate en torno al desarrollo, la democracia o la gobernabilidad en Honduras. La RED es el convencimiento a partir de una receta, en función de la desesperación que se vive en Honduras, para volver a crecer económicamente y con ello recomponer el modelo institucional y dar una respuesta a la crisis.

William Easterly, profesor de la Universidad de Nueva York, economista y especializado en desarrollo, citado por Wessel, refiriéndose a la "Ciudad Modelo" dice: "Es una combinación de gran creatividad y gran ingenuidad" ${ }^{20 "}$.

La ciudad modelo no es un problema de Estado de Derecho - hipotecar la "soberanía" nacional y/o de gobiernos garantes- es un problema de condiciones materiales y sociales requeridas por el capital para su funcionamiento. Los inversionistas, nacionales o extranjeros, además de reglas claras demandan de una serie de condiciones que eficiente al máximo su inversión. Por ejemplo: carreteras, puertos y aeropuertos de calidad; Romer lo dice: "Hay que pensar en grande, señalo. Pidió la construcción de un aeropuerto lo suficientemente grande como para ser un centro hemisférico de conexiones, dijo $0^{21 " .}$.

Para solicitar esto en Honduras y/o proponérselo construir hay que ser muy creativo o muy ingenuo. El Estado de Honduras y la administración actual tienen una reputación internacional muy dañada a raíz del golpe de Estado al Presidente Manuel Zelaya Rosales en junio del 2009, además de otras tendencias históricas: violación de derechos humanos, corrupción, débil institucionalidad, etc. En estas condiciones el Estado de Honduras y la administración actual no son objeto de crédito internacional para hacer una inversión pública de tal naturaleza: un aeropuerto que sea centro hemisférico de conexiones.

El capital privado tampoco va a construir un aeropuerto que sea centro hemisférico de conexiones. Sao Paulo y Bogotá son en primer y segundo lugar, respectivamente, los mayores aeropuertos de tráfico aéreo y centro de conexiones en América Latina. Las líneas aéreas regionales: Copa y Taca han hecho de los aeropuertos de ciudad Panamá, Lima y San Salvador sus centros de conexiones. ¿En cuánto tiempo un aeropuerto en una ciudad hondureña modificara las tendencias de conexiones aéreas de estos cinco aeropuertos de ciudades latinoamericanas para constituirse en un centro hemisférico de conexiones?

\footnotetext{
${ }^{20}$ Op. Cit.

${ }^{21}$ Op. Cit.
} 
Además de la construcción de la infraestructura —aeropuerto— se requieren otras condiciones materiales y sociales: industria hotelera, energía eléctrica, seguridad, población educada en cultura turística, etc. Esas condiciones que el inversionista requiere para hacer eficiente al máximo su inversión de capital las debe proporcionar el Estado de Honduras. La receta del señor Romer incluye pensar en grande. Antes que el tamaño del pensamiento, lo importante es pensar; hay que comenzar por el primer paso, caso contrario, como bien señala William Easterly, lo que poseemos y hacemos es una creatividad ingenua.

Para superar estas concepciones ingenuas del crecimiento y/o del desarrollo regional es que el conocimiento científico ha elaborado un cumulo de conocimientos en torno a la problemática del desarrollo regional. Son décadas de pensamiento y producto de ello la humanidad cuenta con una serie de teorías como: planificación por cuencas hidrográficas, nódulo/lugar central, polos de crecimiento, teoría de la localización, etc. Es evidente que en el abordaje del modelo de gestión pública: REP o ciudad modelo el debate científico ha estado ausente y, en esencia, ha sido y es un problema de orden ideológico. La UNAH desde su política de investigación y mediante este artículo intenta contribuir a enriquecer el abordaje de la problemática en cuestión.

\section{El fracaso del Estado de derecho en Honduras y el "sueño" de Paul Romer.}

No dudamos de la calidad del video de la presentación del Señor Romer, y del contenido de la presentación misma; dudamos de su condición de respuesta científica a la problemática del desarrollo regional y nacional de Honduras. El desarrollo no es un tema de recetas; es decir de suma de ingredientes. El desarrollo es una relación social de concepción del mundo y de los seres humanos; es un problema ontogénico; es un proceso construido a lo largo de un tiempo histórico y un espacio geográfico en el cual sus habitantes - ciudadanos- auto-construyen su dignidad humana.

El Presidente Porfirio Lobo se fue hace dos años a Corea del Sur y Singapur a ver las condiciones/característica que Romer le ha conferido a su modelo ideal de ciudad modelo: 1. El tamaño aproximado de Hong Kong, 1,000 kilómetros cuadrados; 2. Territorio estatal; 3. Respeto a las reglas a partir de un país bien gobernado, "algo parecido a lo que los británicos hicieron en Hong Kong". La RED planteada por Romer no existe en la realidad; lo que existe son las condiciones/característica que Él le confiere al modelo. Romer lo que le propuso al Presidente Lobo y sus más cercanos colaboradores fue un "modelo" —en el pleno sentido de la cultura renacentista: un arquetipo- - Un modelo es algo que oriente hacia dónde ir, algo a lo 
que deseamos parecernos, algo que nos gustaría ser. El término modelo proviene del concepto italiano de modello. La categoría puede utilizarse en distintos ámbitos y con diversos conceptos. Aplicado al campo de los estudios del desarrollo, un modelo hace referencia al arquetipo que, por sus características idóneas, es susceptible de imitación o reproducción. También se utiliza para referirse al esquema teórico de un sistema o de una realidad compleja.

Cabe señalar que Romer define condiciones/característica del modelo: a) a nivel físico: tamaño y b) a nivel jurídicas: territorio estatal y nuevas reglas del juego. Teniendo como única fuente de información las noticias antes señalas, no sabemos si Romer define características socio-culturas al modelo como las que posee Hong Kong: cero violencia, cero corrupción, mano de obra con alto nivel de instrucción y formación, polo de atracción poblacional y de inversión de capital, estabilidad institucional, tradición de eficiencia, etc. Los opositores a la RED en Honduras lo dicen, y Wessel lo señala: "un enclave libre de viejas leyes y prácticas". El modelo propuesto por Romer requiere de leyes nuevas. "No puedo cambiar las reglas en medio del partido", asevero, mientras detrás de él aparecía una fotografía de un partido de fútbol en la pantalla. "Hay que crear un nuevo campo de juego y ver si alguien quiere jugar ${ }^{22 "}$.

Romer habla de un "nuevo campo de juego" —RED_y de cambio de reglas. Los opositores a la ciudad modelo en Honduras temen de las nuevas reglas y plantean que allí el Estado de derecho, especialmente a nivel laboral, no será vigente y los trabajadores desprovistos de toda protección jurídica serán sometidos por la voracidad del capital. Esa preocupación es válida, pero también revela una forma de pensamiento y un desconocimiento de las formas de funcionamiento del capital a nivel global: imagen. A ninguna firma de capital, consecuentemente a la imagen del mercado de las marcas que comercializan, le interesa presentarse a nivel mundial como un capitalista del siglo XVIII o XIX; es decir sin tener en consideración el carácter de agente de consumo de los trabajadores, sujetos de política social y ciudadanos de un Estado de derecho. He allí porque muchas de las grandes marcas internacionales sub contratan fases del proceso de producción de las mercancías que comercializan.

Es decir, el debate va mas allá de la intensidad con que el capital hace uso de la mano de obra - como ideologizan los críticos del modelo en Honduras-. También incluye otra serie de aspectos como: tipo de mano de obra, Estado de derecho que

${ }^{22}$ Op. Cit. 
legitima y garantiza el intercambio capital-trabajo, etc. Wesel dice que el enclave — ciudad modelo- debe estar libre de viejas leyes y viejas prácticas. He allí el verdadero reto y las limitantes del sueño de una ciudad modelo como Hong Kong en Honduras: las viejas leyes es fácil eliminarlas, el Congreso Nacional puede derogar las viejas leyes y emitir nuevas leyes. La pregunta de fondo es otra: ¿quién y cómo se eliminan las viejas prácticas sociales, especialmente las que hacen ineficiente la calidad de vida del hondureño, y "construye nuevas prácticas" sociales en Honduras?. La noticia "Viaje. Corea del Sur y Singapur serán los países que visitará. Lobo viajará a Asia para conocer ciudades modelo" no habla de nuevas prácticas, se queda en "reglas especificas y diferentes a las del resto del país" ${ }^{23 "}$. Pero sin utilizar la categoría nuevas prácticas plantea una: "El proyecto de las ciudades modelo consiste en la creación de un espacio dentro del territorio en donde se garantice una convivencia armónica... ${ }^{24,}$

¿Es posible una convivencia armónica en Honduras en tanto nueva practica requerida para construir la RED? Nuevamente: ¿quién y cómo se eliminan las viejas prácticas del conflicto social, de la corrupción, de la impunidad, etc. y se construyen nuevas prácticas de convivencia armónica en Honduras? Quién lo va a hacer: ¿El sistema educativo? ¿Las Iglesias? ¿La familia? ¿Los medios masivos de comunicación? ¿El Estado? ¿El gobierno? ¿La administración pública actual? ¿Un consultor nacional o internacional? ¿La sociedad civil? ¿Las Ong's? ¿Dios? ¿El pensamiento mágico? Si asumimos una concepción científica de la historia - proceso-implica reconocer que las nuevas o viejas prácticas son sociales y que, en tanto construcciones sociales, existen instituciones sociales que las construyen, socializan y legitiman.

El Presidente Porfirio Lobo fue a Corea del Sur y Singapur; no fue a China, país al que pertenecen las regiones especiales de Hong Kong y Macao; "...para seguir adelante con la ambiciosa iniciativa... ${ }^{25 n}$. Viajar es importante; de hecho, viajar es vivir; pero para seguir adelante con la ambiciosa iniciativa, además de viajar, se necesitan otras nuevas prácticas en Honduras. Tomando a Hong Kong como referente; Hong Kong tiene practicas de vida individual y social que Honduras no posee - pero que puede llegar a poseer-.

El proyecto de las ciudades modelo se impulsa bajo reglas específicas y diferentes a las del resto del país. ¿Por qué necesitan ser diferentes las reglas entre el resto de

\footnotetext{
${ }^{23}$ La prensa $(4: 02: 10)$

${ }^{24}$ IBIDEM

${ }^{25}$ Op. Cit.
} 
Honduras y la RED? En la RED no habrá corrupción, ni ineficiencia pública y privada, ni violencia personal e institucional, etc. ¿Por qué entonces en el resto de Honduras si deben perpetuarse las viejas prácticas de corrupción, impunidad, ineficiencia institucionalizada, violencia, etc.? ¿Por qué?. Porque para que la inversión privada internacional venga a darle vida a la RED demanda condiciones de funcionamiento materiales y sociales que potencialicen su inversión: cero violencia, cero corrupción, mano de obra con alto nivel de instrucción y formación, polo de atracción poblacional y de inversión de capital, estabilidad institucional, tradición de eficiencia, etc. Prácticas sociales que el gobierno reconoce no puede cambiar en el territorio hondureño.

Romer, quien le comercializa la idea al Presidente Porfirio Lobo, no confía en nuestro Estado de derecho y en nuestra cultura institucional; es más, reconoce que ni a nivel de la "ciudad modelo" puede ser garante de las "reglas" y por ello plantea que haya "un país bien gobernado, digamos Noruega o Canadá, para que sirva de "garante" y le asegure a los inversionistas y habitantes que se respetaran las reglas,... ${ }^{26 "}$. Esto equivale al pleno reconocimiento del fracaso del Estado de derecho en Honduras. Un Estado que no es "garante" de su propia institucionalidad, de su propia normativa, de su propio desarrollo, de su propia población, etc. Es decir, un país mal gobernado, digamos Honduras: "Un país lo suficientemente desesperado" como para intentar una "audaz" idea: fundar una "ciudad modelo".

Se entrecomillamos "audaz" porque se coincide con William Easterly, la "ciudad modelo": "Es una combinación de gran creatividad y gran ingenuidad". Tavel Otero, un empresario local, reconoce la dimensión del planteamiento en términos de su impacto en el Estado de derecho dice: "Pero no creo que se pueda promocionar la idea diciendo a los hondureños que nuestras leyes son tan malas que hay que

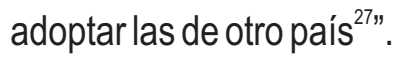

Sólo un país tan desesperado como Honduras puede dedicarle tiempo institucional y recursos públicos a un planteamiento que no es una teoría científica del desarrollo regional, ni un modelo de desarrollo, ni un modelo de gestión pública. Es un "sueño", una "inusual idea", una "receta". Wessel dice que "Parece simple pero es el tipo de hallazgo que lo podría hacer acreedor a un Nobel ${ }^{28 "}$. Veamos un referente. Milton Friedman, uno de los más importantes economistas de la segunda mitad del siglo XX. Premio Nobel de Economía en 1976 "por sus resultados en los campos del

\footnotetext{
${ }^{26}$ La Prensa (3:02:10)

${ }^{27}$ IBIDEM

${ }^{28}$ LaPrensa
} 
análisis del consumo, historia y teoría monetaria y por su demostración de la complejidad de la política de estabilización". Friedman fue un monetarista. Economista empírico, era especialista en estadística y econometría. Defensor del libre mercado, fue el más conocido líder de la Escuela de Chicago. Se opuso al keynesianismo en el momento de máximo apogeo de éste, en los años cincuenta y sesenta. Asesoró a multitud de gobiernos, muchos de los cuales aplicaron sus propuestas. Tan popular como polémico ${ }^{29}$.

Partiendo del referente anterior, Milton Friedman; los hondureños, en particular y los pueblos de América Latina, en general ya sabemos por experiencia, por vivencia lo que conllevaron los procesos de ajuste estructural fundamentados en sus propuestas: crecimiento económico sin desarrollo, déficit de desarrollo social, problemas de gobernabilidad, priorizar el pago de la deuda externa en detrimento del gasto social, dolor, muerte, etc. Bien por él, obtuvo un premio nobel y sus propuestas son la normativa que aplica el Banco Mundial y el Fondo Monetario Internacional. Pero: ¿han conducido los ajustes estructurales, fundamentados en los planteamientos del premio nobel Milton Friedman, al desarrollo de Honduras?.

Romer, un ex académico de la Universidad de Nueva York y hoy empresario de la educación, se fundamenta en los principios de Milton Friedman y desde un planteamiento empírico — receta— busca "observar el experimento ${ }^{30}$ ". El éxito del experimento — ciudad modelo— puede hacer acreedor a un Nobel a Romer, dice Wessel. Entonces, la "ciudad modelo" además de ser un "sueño", una "inusual idea", una "receta", es un "experimento" a observar. En conclusión: el gobierno de Honduras presidido por el Señor Porfirio Lobo, pese a tener un "Plan de Nación" fundamentado en el humanismo cristiano, está "experimentando" con la vida de los hondureños a partir de un "sueño".

¿Contribuye el Presidente Porfirio Lobo a la democracia y gobernabilidad de Honduras cuando su administración define como modelo de gestión pública la RED?

Visto desde esta perspectiva el tema de la RED no es un tema de debate científico/académico ya que los sueños no se debaten, se "duermen" y/o se constituyen en un medio para evadir una realidad en "un país lo suficientemente desesperado" en donde ni el gobierno, ni las diferentes administraciones públicas, ni la sociedad organizada como sociedad civil asumen su propia responsabilidad histórica. Lo que los hondureños debemos estar debatiendo no es la RED;

\footnotetext{
${ }^{29} \mathrm{http}: / /$ www.eumed.net/cursecon/economistas/Friedman.htm

${ }^{30}$ LaPrensa. (3:02:10)
} 
debatamos en torno al desarrollo del país en función de nuestras potencialidades y debilidades como sociedad, la dinámica del mercado mundial y nuestra inserción en ese mercado; a partir de una ética que tenga como fundamento la dignidad humana de los hondureños.

\section{En época electoral el tema cobra vigencia.}

Durante los primeros meses del año 2010 el tema de la ciudad modelo tuvo vigencia y luego fue desapareciendo del escenario de noticias hasta extinguirse. Aproximadamente quince meses después, es decir hoy: época de elecciones primarias, el tema cobra actualidad nuevamente y quien mayor usufructo obtiene del tema es el Abogado Juan Orlando Hernández, Presidente del Poder Legislativo y quien aspira a ser electo candidato a la presidencia de Honduras por el Partido Nacional. Informa el diario La Prensa en su edición electrónica del día martes 4 de septiembre del año 2012 que se "Firman convenio para primera ciudad modelo" 31 ".

Plantea el rotativo que la empresa inversionista es la estadounidense MKG o MGK, la inversión inicial será de 15 millones de dólares, la primera RED se construirá en Trujillo, en la costa norte hondureña, y los trabajos se iniciaran en octubre. El testigo de la firma del convenio y que calificó ese momento como de gran trascendencia para Honduras fue Juan Hernández, Presidente del Congreso. En un momento de recesión económica mundial y Honduras bajando cuatro posiciones - del lugar 86 al 90- en el Informe Mundial de Competitividad que incluye 144 países; las condiciones económicas mundiales y nacionales hacen que la noticia no sea creíble; Honduras no constituye, ni representa un país atractivo para la inversión. Lo que ocurra en octubre (¿año?) determinara la veracidad de la noticia.

Lo único interesante de toda esta situación es como el Presidente del Congreso, Abogado Juan Orlando Hernández hace que su tema de campaña —las ciudades modelo o RED - se convierta en un tema noticioso y el conjunto de movimientos políticos de los diferentes partidos políticos terminen discutiendo su tema; es decir, Él les ha definido el tema de la agenda política.

\section{CONCLUSIONES}

1) El denominado modelo de gestión RED no contribuye a la democracia y

\footnotetext{
${ }^{31}$ La Prensa (4:10:12) http://www.laprensa.hn/Secciones-Principales/Honduras/Tegucigalpa/Firman-conveniopara-primera-ciudad-modelo
} 
gobernabilidad de la sociedad hondureña. No es o no puede ser conceptualizado como una "transformaciones histórica del Estado hondureño en el contexto internacional, nacional o local y/o como una reconfiguración de lo local"; para usar algunas categorías propuestas por la UNAH en su política de investigación científica.

Pese a que representa una reforma de orden constitucional la propuesta jurídica de la RED es más correcta denominarla a nivel de conocimiento de sentido común, como propone David Wessel, como: "... audaz idea: fundar una ciudad modelo, un enclave libre de viejas leyes y prácticas" en un "un país lo suficientemente desesperado".

Lo anterior no niega la importancia de realizar un análisis desde la democracia y la gobernabilidad del Decreto de la Ciudad Modelo o RED.

2) La dinámica política, social e institucional de reforma constitucional que constituye el Decreto Ley de de Ciudad Modelo contribuye a la reproducción institucional de los grupos que manejan los partidos políticos, nacionalista en este caso, en Honduras.

Las RED no son una política/programa de desarrollo regional, ni un proyecto de desarrollo local, ni un modelo de gestión público; son, en esencia, un acto de demagogia $^{32}$ política propuesto por la administración del Presidente Porfirio Lobo Sosa, en el Poder Ejecutivo, y Juan Orlando Hernández, en el Poder Legislativo.

Su finalidad principal es crear "esperanzas" en el pueblo de Honduras; un pueblo duramente golpeado por el desempleo, los bajos niveles adquisitivos y el alto costo de vida. El discurso está dirigido al pueblo y dentro de ese pueblo a los pobres y marginados, en tanto masa electoral; las RED, según los legisladores, constituirán una oportunidad de empleo, educación y salud, en condiciones de sostenibilidad económica y ambiental.

3) El abordaje de las RED ha sido totalmente ideológico. La carencia de referentes teórica y metodológica de carácter científico a lo largo de las discusiones ha dado como resultado la ideologización del tema y se asume desde posiciones partidarias a nivel político.

\footnotetext{
${ }^{32}$ Demagogia es una estrategia utilizada para conseguir poder político. Consiste en apelar a prejuicios, emociones, miedos y esperanzas del público para ganar apoyo popular, frecuentemente mediante el uso de la retórica y la propaganda. http://es.wikipedia.org/wiki/Demagogia
} 
Pese a ser un tema de gestión pública; de desarrollo nacional, regional y local; de ordenamiento territorial; de configuración urbana; de Estado de derecho, etc. el conjunto de la sociedad hondureña ha estado ausente, en términos de aportar al debate desde el conocimiento científico, y el tema se ha constituido en un tema político partidario. Ejemplo: el decreto ley que da vida a las RED y su posterior puesta en práctica tiene un impacto directo en la descentralización y gobiernos locales, en la redefinición de límites territoriales y en la reconfiguración de lo local; por ende es un tema de orden municipal y tanto la ciudadanía, como los gobiernos locales y la Asociación de Municipios de Honduras (AMHON) han estado ausentes del debate.

4) Se inicia este articulo citando el pensamiento de Lewis Carrol y expresado en "Alicia en el País de las Maravillas".

¿QQuieres decirme el camino que debo de tomar para salir de aquí?

-ExclamoAlicia.

Eso depende mucho del lugar al que quieres ir — dijo el gato.

Poco me preocupa a donde ir-dijoAlicia.

Entonces poco importa el camino que tomes —replico el gato".

Hace algunos años Gustavo Bueno ${ }^{33}$ creo la categoría y el concepto de "Pensamiento Alicia", basado en la lógica de la obra literaria "Alicia en el País de las Maravillas", para referirse al modelo de gestión pública impulsado por el Ex Presidente José Luis Rodríguez Zapatero (2004 - 2011) en España. En Honduras no puede aplicarse la categoría de "Pensamiento Alicia" a la administración del Presidente Porfirio Lobo Sosa, pero si el espíritu de la conversación entre Alicia y el gato en la obra literario "Alicia en el País de las maravillas".

Para un gobierno, para una sociedad que no le preocupa "a donde ir" no tiene importancia el camino que tome. Es desde esta lógica que hay comprender la aceptación de la idea y posterior aprobación a nivel constitucional por el gobierno de Honduras de un modelo de gestión denominado "Ciudad Modelo o Regiones Especiales de Desarrollo". El gobierno de Honduras no sabe "a donde ir" y de ahí que la "lógica ciudad modelo" vaya imponiéndose poco a poco en la administración pública del Estado de Honduras. Así como se plantea que la RED es un modelo de gestión pública; también se plantea que Amable de Jesús Hernández, alcalde del municipio de Colinas en el Departamento de Santa Barbará, ha creado y

\footnotetext{
${ }^{33}$ Gustavo Bueno Martínez (Santo Domingo de la Calzada, 1924) es un filósofo español, autor del sistema filosófico denominado materialismo filosófico.
} 
establecido un modelo de salud primaria y comunitaria y que la Rectora de la UNAH, Licenciada Julieta Castellanos ${ }^{34}$, está impulsando un modelo de administración/salud publica en el Hospital Escuela. Se ha llegado al punto que el Poder Ejecutivo aprobó un decreto que permite la implementación a nivel nacional del "modelo demostrativo integral de atención primaria en salud familiar comunitario" que se ejecuta en el municipio de Colinas, Santa Bárbara, también bajo la coordinación de la UNAH. "Este es un modelo parecido al que se implementa en Cuba, en donde los profesionales de la medicina visitan y dan seguimiento a sus pacientes para evitar que estos tengan que trasladarse a los centros hospitalarios ${ }^{35 n}$. La decisión tomada por el ejecutivo para traspasar la administración del hospital Escuela a la Universidad Nacional Autónoma de Honduras (UNAH) tuvo como fundamento: "Por su parte el presidente de la República, Porfirio Lobo, escribió en su cuenta de Twitter que "la administración pasa a manos de la institución que tiene la mayoría de los profesionales más preparados en salud del país: la UNAH ${ }^{36 ! \prime}$

¿Es la UNAH la institución que tiene la mayoría de los profesionales más preparados en salud del país o es el Ministerio de Salud? y/o cual es la función de la UNAH en términos de la Constitución de la Republica. "ARTICULO 160.- La Universidad Nacional Autónoma de Honduras es una Institución Autónoma del Estado, con personalidad jurídica, goza de la exclusividad de organizar, dirigir y desarrollar la educación superior y profesional. Contribuirá a la investigación científica, humanística y tecnológica, a la difusión general de la cultura y al estudio de los problemas nacionales. Deberá programar su participación en la transformación de la sociedad hondureña ${ }^{37 "}$. No es función de la UNAH administrar y/o prestar "el derecho a la protección de la salud;" (ARTICULO 145) su función por definición constitucional es: organizar, dirigir y desarrollar la educación superior y profesional en Honduras.

Con lógicas perversas de esta naturaleza se terminara pasándole la administración del sistema penitenciario de Honduras a las maras y/o a los carteles de la droga porque tiene la mayoría de los profesionales más preparados del crimen en el país. Con culturas políticas de esta naturaleza no es posible construir Estado de derecho en Honduras y desarrollo de la institucionalidad publica. Para las RED el modelo es Hong Kong o Singapur; para salud el modelo es Cuba. Para la RED el ideólogo es

\footnotetext{
${ }^{34}$ La titular de la UNAH además se comprometió a respetar "...vamos a convertir en el ejemplo en el modelo de salud pública de Honduras". http://www.radiocadenavoceshn.com/rcv/todas-lasnoticias/nacionales/traspasan-administracion-del-hospital-escuela-a-la-unah.html

${ }^{35}$ El Heraldo (10:07:12)

${ }^{36}$ El Heraldo (10:07:12)

${ }^{37}$ Constitución de la República de Honduras. Decreto No 131 del 11 de enero de 1982. 2002.
} 
Paul Romer; para la atención primaria en salud familiar comunitaria el ideólogo es Amable de Jesús Hernández, para la administración/salud pública en el Hospital Escuela la ideóloga es Julieta Castellanos, etc.

¿Cuál es el referente jurídico último de esta diversidad de "modelos"? ¿Qué papel desempeña el Estado de derecho y el orden constitucional en esta amplia gama de definición de "modelos"? ¿Cuál es la lógica que une o conecta esta multiplicidad de "modelos" en términos de democracia y gobernabilidad? ¿Puede crear, proponer 0 implementar un "modelo" cualquier hondureño en cualquier área de la vida social?. En un país como Honduras en donde poco preocupa a donde va, entonces poco importa el camino que tome. El efecto perverso de la "lógica ciudad modelo" es la destrucción del orden democrático y la ingobernabilidad a nivel social.

\section{AGRADECIMIENTO}

A mi familia: apoyo y comprensión critico; cuya construcción, compañía e intercambio continuo a través del amor y el dialogo me ayudan a crecer. Gracias Ligia, Irene y Rubenia.

\section{BIBLIOGRAFÍA}

\section{Libros:}

Bueno Martínez, Gustavo. Zapatero y El Pensamiento Alicia. $1^{\text {a }}$ ed., Madrid, Temas de Hoy, 2006.

Constitución de la Republica de Honduras. Decreto No 131 del 11 de enero de 1982. 1a . Edición, Tegucigalpa, Edigrafic S. de R.L., 2002.

Ocampo, José E. ¿Hacia un Nuevo Modelo de Desarrollo? Un debate. $1^{\text {a }}$ ed., Bogotá, tercer Mundo, 1997.

Roitman Rosenmann, Marcos. Pensar América Latina. $1^{\text {a }}$ ed., Buenos Aires, CLACSO. 2008.

\section{Periódico:}

"El sueño de una "ciudad modelo" como Hong Kong en Honduras". La Prensa. San Pedro Sula, Honduras (3:02:10) Pág. 70.

"Viaje. Corea del Sur y Singapur serán los países que visitará. Lobo viajará a Asia para conocer ciudades modelo". La Prensa. San Pedro Sula, Honduras (4:02:10) Pág. 20. 
Página Web:

"Convenio interinstitucional. Gobierno de Honduras traspasa administración del Hospital Escuela a la UNAH"

http://www.radiocadenavoceshn.com/rcv/todas-las-noticias/nacionales/ traspasan-administracion-del-hospital-escuela-a-la-un. El Heraldo (10:07:12)

Decreto de Ciudad Modelo (Regiones Especiales de Desarrollo). Dictamen. http://www.congresonacional.hn/

Martinez Coll, Carlos y Rocasolano, Pablo. "Milton Friedman(1912-2006)"

Emuned.net/http://www.eumed.net/cursecon/economistas/Friedman.htm. 2007.

Redaccion@laprensa.hn "Firman Convenio para Primer Ciudad modelo" http://www.laprensa.hn/Secciones-Principales/Honduras/Tegucigalpa/ Firman-convenio-para-primera-ciudad-modelo. La Prensa (4:10:12) UNAH. Prioridades de Investigación UNAH, 2012-2016. Ejes y Temas prioritarios. https://www.unah.edu.hn 